\title{
Energy and Exergy Balances for Modern Diesel and Gasoline Engines
}

\author{
G. Bourhis* and P. Leduc \\ Institut français du pétrole, IFP, 1-4 avenue de Bois-Préau, 92852 Rueil-Malmaison Cedex - France \\ e-mail: guillaume.bourhis@iff.fr - pierre.leduc@ifp.fr \\ *Corresponding author
}

Résumé - Bilans d'énergie et d'exergie pour des moteurs Diesel et essence récents - L'objectif est ici d'évaluer la différence entre bilan d'énergie et d'exergie (ou énergie utile) pour des moteurs à combustion interne lorsque la problématique de récupération d'énergie est prise en compte. Dans le premier cas, l'entropie du système n'est pas considérée, si bien que le travail utile maximal qu'il est possible de récupérer d'un système ne peut pas être estimé. Tandis que le second cas est bien mieux adapté pour estimer le potentiel de la récupération d'énergie. Dans cet article, deux moteurs modernes sont étudiés. Le premier est un moteur essence récent, 3 cylindres, de cylindrée réduite, à faible frottement, et le second un moteur Diesel à injection directe à rampe commune, également de cylindrée réduite. Pour chacun de ces deux moteurs, à l'aide de données expérimentales obtenues sur banc moteur, deux bilans d'énergie et d'exergie ont été effectués pour deux points de fonctionnement à charge partielle, représentatifs du cycle NEDC. Dans le cas du moteur Diesel, le travail effectif, représentant environ $30 \%$ et $55 \%$ de l'énergie introduite dans la chambre de combustion, est perdu (sous forme de chaleur), et plus spécifiquement dans les gaz d'échappement, l'eau de refroidissement et l'huile. Mais, lorsque l'on considère le bilan d'exergie, seulement $12 \%$ de l'exergie totale introduite par l'intermédiaire du carburant peut être récupérée afin de produire un travail utile. Dans l'hypothèse d'un rendement de récupération de $25 \%$, le rendement du moteur Diesel pourrait être augmenté de $10 \%$. Dans le cas du moteur essence, l'augmentation de rendement pourrait même atteindre $15 \%$.

\footnotetext{
Abstract - Energy and Exergy Balances for Modern Diesel and Gasoline Engines - The aim is here to evaluate the difference between the energy and exergy (or available energy) balances when heat recovery is considered in an internal combustion engine. In the first case, the entropy of the system is not taken into account so that, the maximum useful work recoverable from a system can not be estimated. Then, the second case is much more adapted to estimate heat recovery potential. In this paper, two modern engines are evaluated. First, an up-to-date gasoline engine: three-cylinder, downsized, low friction, then a modern common rail downsized Diesel engine. For each one, two energy and exergy balances are given for two different part-load operating points representative of the NEDC cycle using experimental data from steady state engine test benches. For the Diesel engine, it is shown that effective work represents around $30 \%$ and that around $55 \%$ of the energy introduced into the combustion chamber is lost (in the form of heat), especially in exhaust gas, in water coolant and oil. But when considering exergy balance, only $12 \%$ of the total exergy introduced through the fuel can be recovered, in order to produce useful work. Expecting a $25 \%$ exergy recovery efficiency, the effective engine efficiency could be increased by 10\%. For the gasoline engine, the increase of the output work could be around $15 \%$.
} 


\section{GLOSSARY}

$\begin{array}{ll}\text { BMEP } & \text { Break Mean Effective Pressure } \\ \text { DPF } & \text { Diesel Particulate Filter } \\ \text { EG } & \text { Exhaust Gas } \\ \text { EGR } & \text { Exhaust Gas Recirculation } \\ \text { HE } & \text { Heat Exchanger } \\ \text { HHV } & \text { Higher Heating Value } \\ \text { IC } & \text { Internal Combustion (engine) } \\ \text { LHV } & \text { Lower Heating Value } \\ \text { NEDC } & \text { New European Driving Cycle } \\ \text { SI } & \text { Spark Ignition } \\ \text { TWC } & \text { Three-Way Catalytic Convertor }\end{array}$

\section{ABBREVIATIONS}

$C_{p} \quad$ Specific heat value

Ex Specific exergy

$h \quad$ Specific enthalpy

$\dot{m}$ Mass flow

$P \quad$ Pressure

$P_{0} \quad$ Reference pressure $(1013 \mathrm{hPa})$

$Q \quad$ Heat exchanged

$R \quad$ Gas constant

$r \quad$ Specific gas constant

$s \quad$ Specific entropy

$T$ Temperature

$T_{0} \quad$ Reference temperature $(298.15 \mathrm{~K})$

$u \quad$ Specific intern energy

$v \quad$ Volume (of a system)

$W \quad$ Work (between turbine and compressor)

$\eta_{t} \quad$ Turbine efficiency

$\rho \quad$ Density

\section{INTRODUCTION}

Thanks to continuous researches and developments on light and heavy duty engines, their efficiency are still improving but are today limited at best to around $40 \%$. It is commonly admitted that a large part of the energy losses in IC engine is due to heat transfer: heating coolant, oil, exhaust gas and air around the engine (under the hood). A potential way to improve the efficiency is to recover a part of the thermal energy available in exhaust gas or in coolant. Recent researches demonstrate that this well known technique in other fields (for example Combined Cycle Gas Turbine) is now achievable on vehicles [1]. To evaluate the impact of such a new system, one of the first step is to evaluate energy balances in up-to-date IC engines (both gasoline and Diesel). It is important to keep in mind that, energy in IC engine may be available either in the form of work or in the form of heat. And, when heat recovery is considered, a new conversion of the recovered energy into useful work needs to be done, consequently decreasing the overall efficiency of the energy recovery. To achieve relevant energy balances, taking into account heat recovery, the difference between the energy and exergy (or available energy) has to be noticed. In the first case, the entropy (introduced by the second law analysis) of the system is not taken into account so that, the maximum useful work recoverable from a system can not be estimated. Then, the second case is much more adapted to estimate heat recovery potential. In this paper, two serial produced modern engines are studied. First, an up-to-date gasoline engine: three-cylinder, low friction: $1 \mathrm{~L}$ displacement, naturally aspired with intake cam-phaser, then a modern four-cylinder, common rail, downsized Diesel engine: 1.6 L displacement. For each one, two energy and exergy balances are given for two different part-load operating points representative of the NEDC cycle using experimental data from steady state engine test benches.

\section{ENERGY AND EXERGY CALCULATIONS}

\subsection{Energy Calculations}

The energy introduced into the system (i.e. the engine) is calculated by taking into account the amount of fuel introduced. This instantaneous energy is expressed in $\mathrm{kJ} / \mathrm{s}$ so in $\mathrm{kW}$.

\subsection{Exergy Calculations}

Exergy (or available energy or availability) represents the amount of useful work that a system can provide when moving reversibly to the reference environment. Whether the system studied is closed, the exergy can be calculated this way:

$$
E x=\left(u-u_{0}\right)+P_{0}\left(v-v_{0}\right)-T_{0}\left(s-s_{0}\right)
$$

or the system is an open flow system, so the exergy equals:

$$
E x=\left(h-h_{0}\right)-T_{0}\left(s-s_{0}\right)
$$

where $E x$ is the specific exergy, $u$ the specific intern energy, the specific enthalpy, $h$ the specific entropy and $s$ the specific volume of the closed system, $u_{0}, v_{0}, s_{0}$ and $h_{0}$ are the corresponding values at the reference environment conditions: $T_{0}$ and $P_{0}$. In this paper, the atmosphere air is taken as the reference environment where $T_{0}=298.15 \mathrm{~K}$ and $P_{0}=1013 \mathrm{hPa}$. For this study, the exergy is also expressed in $\mathrm{kJ} / \mathrm{s}$ so in $\mathrm{kW}$.

Regarding equations, exergy is based on second law analysis. So, for an isolated system, exergy always decreases or at least remains constant when the process is reversible (no creation of entropy). 
As the energy contained in the fuel is calculated with the Lower Heating Value (LHV) and the exergy contained in the fuel is calculated with the Higher Heating Value (HHV), in this paper, the ratio $\mathrm{HHV} / \mathrm{LHV}$ is taken equal to 1.053 according to Szargut and Styrylska's studies [2].

In exergy balances and especially when heat recovery is considered, it is essential to notice the difference between exergy loss and exergy destruction. Indeed, exergy contained in exhaust gas (for example) is lost if we consider the engine output work, but can be recovered using specific devices. Whereas, exergy destruction, due to the irreversibilities created during combustion process (for example), can not be recuperated and decreases the recoverable exergy.

\section{BALANCES FOR A GASOLINE ENGINE}

In this part, first paragraph will give some details about the global architecture of the gasoline engine. Then, next paragraphs will be devoted to explain how the energy and exergy balances have been obtained for each part of the engine. Finally for this engine, Section 2.7 will recapitulate, thanks to charts, all calculations that have been made, but not necessarily been presented in previous paragraphs.

\subsection{Architecture of the Engine}

Figure 1 shows the global architecture of the considered gasoline engine (three-cylinder, low friction: $1 \mathrm{~L}$ displacement, naturally aspired with admission cam-phaser). The two part

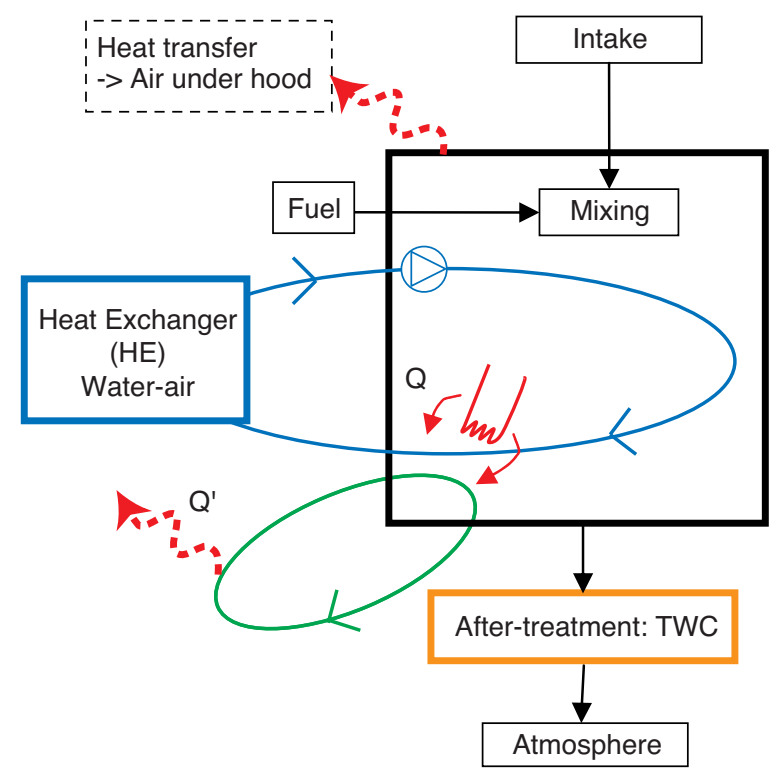

Figure 1

Global architecture of the SI gasoline engine. load operating points studied are here: $2000 \mathrm{rpm}-\mathrm{BMEP}=$ $0.2 \mathrm{MPa}$ and $3500 \mathrm{rpm}-\mathrm{BMEP}=0.5 \mathrm{MPa}$. The first point is representative of a steady-state speed in urban condition and the second, a steady-state speed on highway.

\subsection{Combustion Process}

During the combustion stroke, an important part of the exergy is destroyed, coming from the irreversibilities of the combustion, which means that the exergy gained by the gases is less than the exergy contained in the injected fuel [3]. A simple formula to estimate the exergy destroyed during the combustion stroke is:

$$
\left.\frac{E x_{\text {dest }}}{E x_{\text {fuel }}}\right)_{\text {comb }}=\frac{T_{0}}{T_{1}-T_{0}} \cdot \ln \left(\frac{T_{1}}{T_{0}}\right)
$$

where $T_{1}$ is the adiabatic flame temperature at the end of the combustion [4]. The exergy destroyed, for the operating points studied, during the combustion stroke is calculated thanks to the use of Equation (3) and combustion analysis software for temperature estimation. The result is that combustion irreversibilities represent about $25 \%$ of the exergy introduced.

\subsection{Coolant in Heat Exchanger}

It is considered that all the energy contained in coolant comes from energy losses of the engine and, that all this energy is transferred to atmosphere thanks to the water cooler.

In order to estimate the energy and exergy transferred from coolant to atmosphere in the heat exchanger, hypotheses have been made. Coolant flow in the engine is estimated to $1.1 \mathrm{~L} . \mathrm{kW}^{-1} \cdot \mathrm{min}^{-1}$. The same estimation is made for the Diesel engine, and has been validated with fluid-flow sensor on the Diesel engine. So that, the error revealed is around $10 \%$, which was accepted. Due to a lack of data, the exergy balances have not been performed for the water pump and for heat transfer in cylinder. Moreover, the fluid used to estimate the exergy balance of coolant, is considered to be pure water. Finally, to simplify the calculations, only upstream and downstream heat exchanger temperatures have been taken into account for heat transfer. In addition, the pressure loss in the heat exchanger is neglected.

The exergy variation of water due to temperature variation in the heat exchanger is:

$$
\Delta E x_{\text {water }}=\Delta H_{\text {water }}-T_{0} \Delta S_{\text {water }}
$$

with:

$$
\Delta S_{\text {water }}=\dot{m}_{\text {water }} C_{P_{\text {water }}} \ln \left(\frac{T_{\text {out }}}{T_{\text {inater }_{\text {water }}}}\right)
$$


where $\dot{m}_{\text {water }}$ is the water mass flow in the engine (the same mass flow as in the heat exchanger), $C_{P_{\text {water }}}$ is the water specific heat value and $T_{\text {inwater }}, T_{\text {outwater }}$ are the upstream and downstream heat exchanger water temperatures.

\subsection{Lubricating Oil}

Oil contained in the engine is a commercial lubricant which grade is $5 \mathrm{~W} 40$. Its density is $850 \mathrm{~kg} / \mathrm{m}^{3}$, and its specific heat value is estimated to $1900 \mathrm{~J} \cdot \mathrm{kg}^{-1} \cdot \mathrm{K}^{-1}$. In order to evaluate the exergy variation of oil in the engine, the output temperature has been measured. As seen in Figure 1, there is no heat exchanger for oil on this engine. On vehicle, it is only the airflow under the engine which refreshes its temperature. So, to make energy and exergy balance, the oil temperature variation between output of the engine and input (oil pump) is estimated to $3 \mathrm{~K}$.

\subsection{Three-Way Catalytic Converter (TWC)}

In this part, numerical simulation has been used to estimate the heat transfer or the energy loss in the TWC. To do so, LMS IMAGINE.Lab AMESim ${ }^{\circledR}$ software has been used to estimate the energy lost when the TWC is at thermal equilibrium. This means that energy loss is fitted in order to get the same downstream TWC gas temperature for the experimental and the computed case. Exergy could be recovered here by considering the two part load operating points and a decrease of the conversion rate of $\mathrm{NOx}, \mathrm{CO}$ and $\mathrm{HC}$ from $99 \%$ to around 95\%. Results are shown in Figure 2 to Figure 5.

\subsection{Exhaust Gas}

A large part of energy (and exergy) is contained in exhaust gas in the form of heat. Note that the difference of composition between exhaust gas (e.g.) and atmosphere air is not

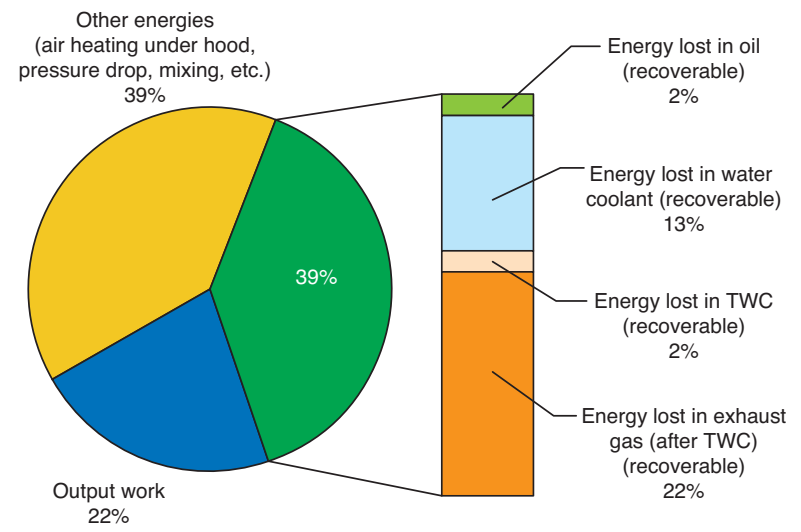

Figure 2

Energy balance for the SI gasoline engine at $2000 \mathrm{rpm}-$ $\mathrm{BMEP}=0.2 \mathrm{MPa}$.

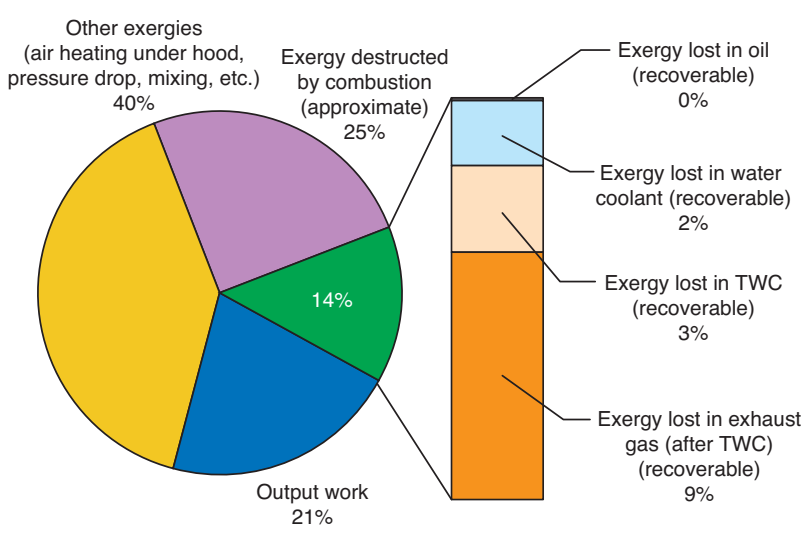

Figure 4

Exergy balance for the SI gasoline engine at $2000 \mathrm{rpm}-$ $\mathrm{BMEP}=0.2 \mathrm{MPa}$.

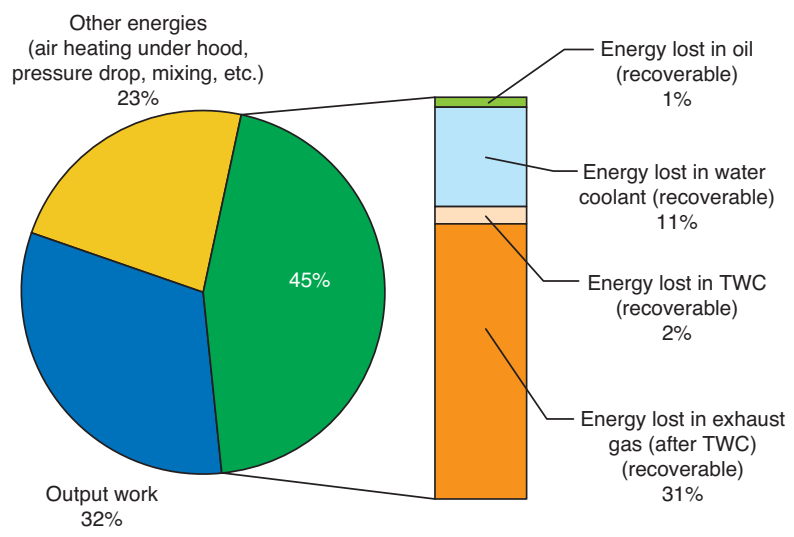

Figure 3

Energy balance for the SI gasoline engine at $3500 \mathrm{rpm}-$ $\mathrm{BMEP}=0.5 \mathrm{MPa}$.

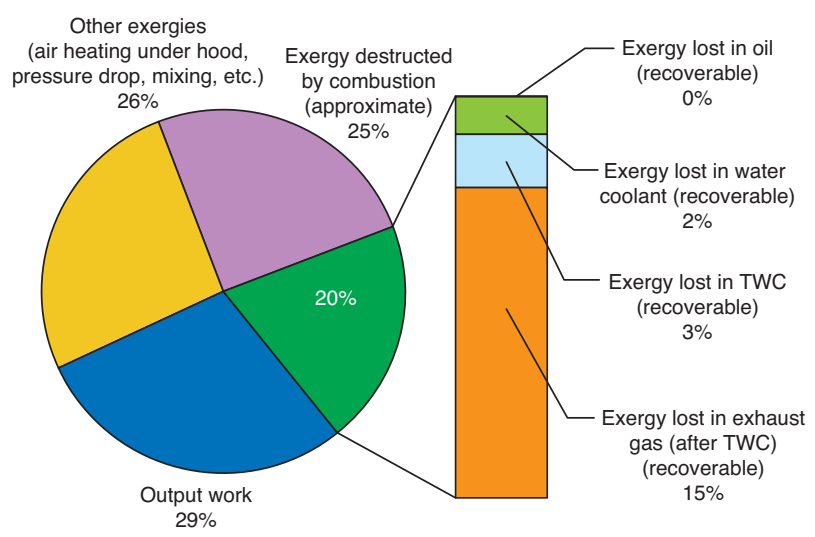

Figure 5

Exergy balance for the SI gasoline engine at $3500 \mathrm{rpm}-$ $\mathrm{BMEP}=0.5 \mathrm{MPa}$. 
considered in this exergy calculation. Considering the working fluid as an ideal gas, to take into account the impact of pressure on entropy so on exergy of the exhaust gas, a term is added to Equation (5) so that Equation (4) becomes:

$$
\Delta E x_{e . g}=\Delta H_{e . g}-T_{0} \times \dot{m}_{e . g} \cdot\left(C_{p_{e . g}} \ln \left(\frac{T_{0}}{T_{e . g}}\right)-r \cdot \ln \left(\frac{P_{0}}{P_{e . g}}\right)\right)
$$

\subsection{Energy and Exergy Balances for a Gasoline Engine}

The different parts above can be summarized as follows.

It has to be noticed, that for these balances, friction loss power is considered to be exclusively transformed into heat, so these energy and exergy losses are implicitly considered in coolant, in oil and a part is also contained in the item "Other" for example in "heating air under hood".

Figure 2 to Figure 5 show the different energy and exergy balances made on two part-load operating points. The term "recoverable" points out the energies and exergies which can be recovered on an engine, by adding a specific device on it. Some of these recoverable energies (exergies) would be more difficult to recover, due to the size and weight of the required device and also its efficiency.

Figures show the difference between exergy and energy balances, especially for the recoverable energy. For example, if we considerer the operating point $2000 \mathrm{rpm}-\mathrm{BMEP}=0.2$ $\mathrm{MPa}$, the energy balance shows that $39 \%$ of the energy introduced into the engine is lost in the form of heat that can be recovered. On the other hand, the exergy balance shows that only $14 \%$ of the exergy introduced into the engine could be converted to useful work. In other words, only $36 \%$ of the recoverable energy could be used again to improve global efficiency of the engine. This ratio is around $44 \%$ for the second operating point: $3500 \mathrm{rpm}-\mathrm{BMEP}=0.5 \mathrm{MPa}$.

Figures also show that output works (torque) are almost the same in the two different balances. This is mainly because they are not containing entropy (as it is a useful work) and the slight difference in percentage comes from the global energy and exergy introduced in the engine (cf. Sect. 1.2 for LHV and HHV notions).

Recent studies showed that an increase of the output work of $15 \%$ is reasonable [1]. This would represent an exergy recovery of about $25 \%$ for both operating points.

\section{BALANCES FOR A DIESEL ENGINE}

In the same way as for the gasoline engine balances, first paragraph will here describe the global architecture of the Diesel engine. Then, next paragraphs will be devoted to explain how balances have been obtained for each part of the engine. Finally Section 3.9 will recapitulate all calculations thanks to charts.

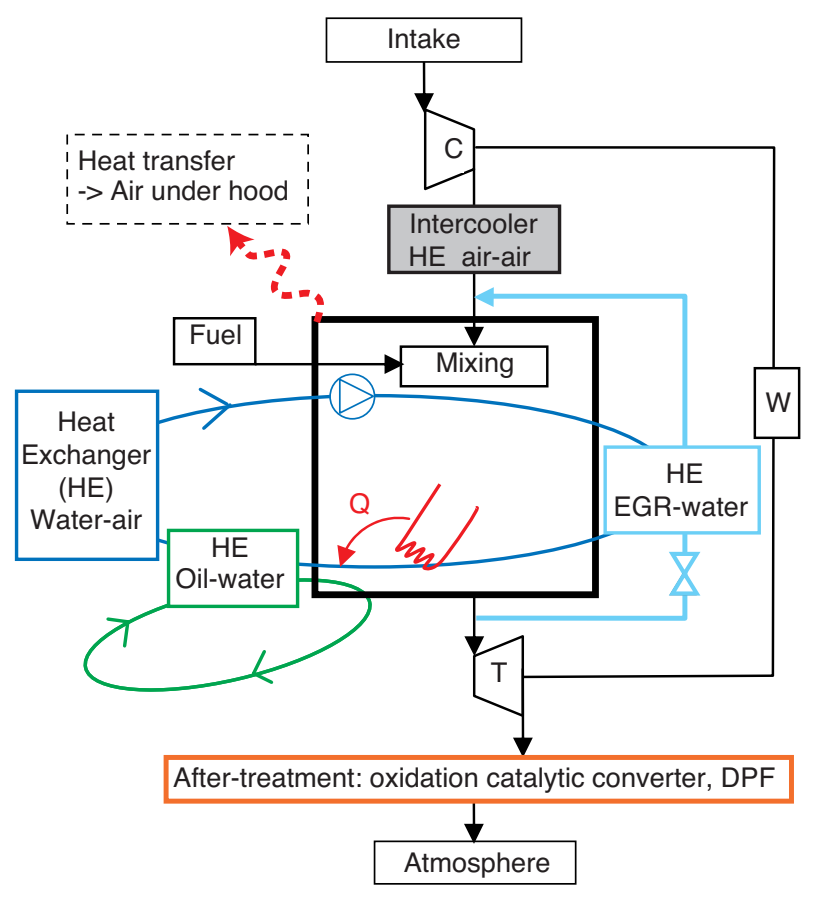

Figure 6

Global architecture of the Diesel engine.

\subsection{Architecture of the Engine}

Figure 6 shows the global architecture of the considered Diesel engine (common rail, 1.6 L displacement). The two part load operating points studied are here: $1500 \mathrm{rpm}-$ $\mathrm{BMEP}=0.3 \mathrm{MPa}$ with $43.2 \%$ EGR (Exhaust Gas Recirculation) and $2300 \mathrm{rpm}-\mathrm{BMEP}=0.8 \mathrm{MPa}$ with $19.7 \%$ EGR. These two points are the same as the gasoline engine if we consider the specific output power. Still, the first point is representative of a steady-state speed in town and the second, a steady-state speed on highway.

Note that $W$ in Figure 6 represents the work on the turbocharger shaft between the turbine and the compressor.

\subsection{Combustion Process}

Proceeding as described in Section 2.2, the exergy destroyed, for the operating points studied, during the combustion stroke, represents about $30 \%$ of the exergy introduced for this compressed ignition combustion.

\subsection{Coolant in Heat Exchanger}

Considering the assumptions of Section 2.3 and the temperature and the coolant mass flow measurements, both the energy and exergy balances have been performed for the water cooler (heat exchanger between engine coolant and atmosphere). 


\subsection{Lubricating Oil}

Oil contained in the engine is a commercial lubricant which grade is 5W30. Considering the same assumptions for oil density, specific heat value and the oil temperature variation as for the gasoline engine (cf. Sect. 2.4), energy and exergy balances have been performed.

\subsection{Coolant in EGR Heat Exchanger}

The Exhaust Gas Recirculation (EGR) is an important part of the engine which allows to meet pollutant requirements. Thus, it is important to know the different temperature of gases and coolant in the different part of the EGR system. In the same way as for the engine water cooler, the coolant mass flow in the EGR heat exchanger has been measured. Temperatures have also been measured. The loss pressure in the heat exchanger is here neglected.

\subsection{Turbo Charging}

From the energy point of view, turbo charging aims to recover part of the energy (and exergy) contained in the exhaust gas in order to transfer it in fresh gases.

Considering the working fluid as an ideal gas, the entropy variation can be approximated with the formula:

$$
\Delta S=\dot{m} \cdot\left(C_{p} \ln \left(\frac{T_{\text {downstream }}}{T_{\text {upstream }}}\right)-r \cdot \ln \left(\frac{P_{\text {downstream }}}{P_{\text {upstream }}}\right)\right)
$$

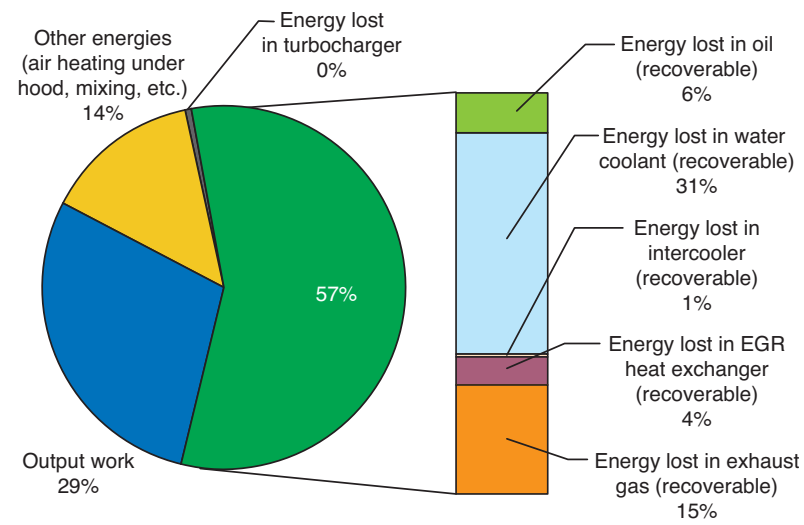

Figure 7:

Energy balance for the Diesel engine at $1500 \mathrm{rpm}-\mathrm{BMEP}=$ $0.3 \mathrm{MPa}$.

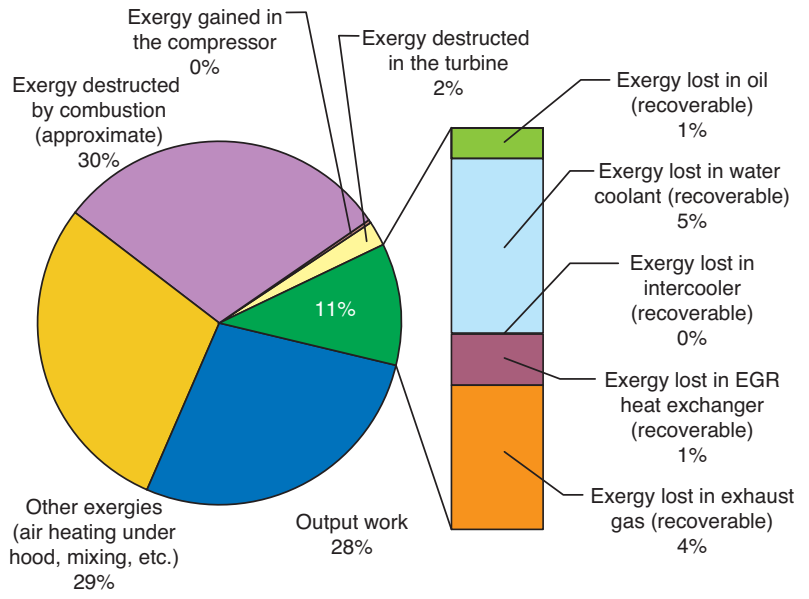

Figure 9

Exergy balance, Diesel engine at $1500 \mathrm{rpm}-\mathrm{BMEP}=0.3$ $\mathrm{MPa}$.

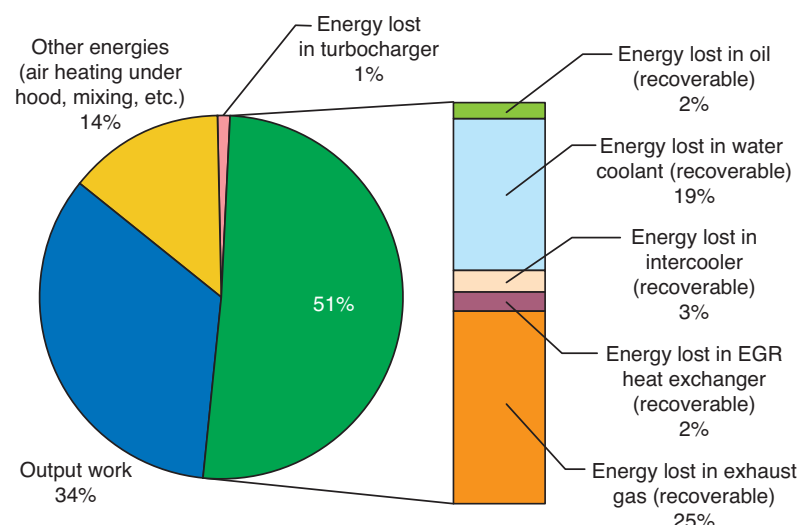

Figure 8

Energy balance for the Diesel engine at $2300 \mathrm{rpm}-\mathrm{BMEP}=$ $0.8 \mathrm{MPa}$.

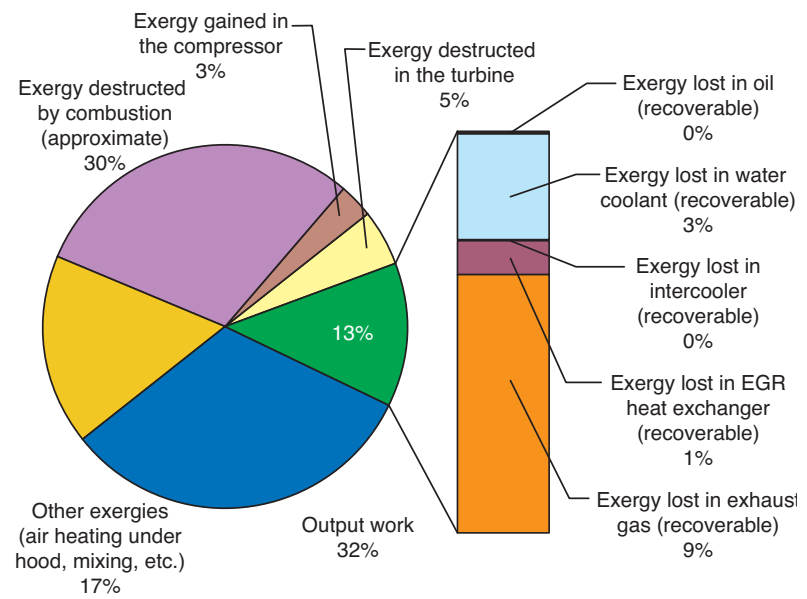

Figure 10

Exergy balance for the Diesel engine at $2300 \mathrm{rpm}-\mathrm{BMEP}=$ $0.8 \mathrm{MPa}$. 
where $\Delta S, \dot{m}, C_{p}, r$ are respectively the entropy variation of the working fluid in the turbine or in the compressor, the fluid mass flow, the specific heat value and the specific gas constant.

Temperatures upstream the turbine are not well measured due to pressure waves in the turbine. Thus, this temperature has been recalculated thanks to a recalculation of the turbine efficiency. To do so, first, we considered no friction on the turbocharger shaft, so the turbine efficiency can be:

$$
\eta_{t}=\frac{\left(\dot{m} C_{p} \Delta T\right)_{\text {compressor }}}{\left(\dot{m} C_{p}^{\prime} \Delta T_{\text {isentropic }}^{\prime}\right)_{\text {turbine }}}
$$

where $\Delta T_{\text {isentropic }}$ is the temperature variation in the turbine considering an isentropic expansion. These values are obtained with the Mollier diagram $(h, s)$ [4]. Then, considering that the turbine efficiency also equals:

$$
\eta_{t}=\frac{\left(T_{\text {upstream }}-T_{\text {downstream }}\right)_{\text {turbine }}}{\left(\Delta T_{\text {isentropic }}\right)_{\text {turbine }}}
$$

the temperature upstream the turbine is recalculated.

Calculations show that around $25-30 \%$ of the exergy contained into the exhaust gas are recovered by the turbine for the two engine operating points studied here. These figures seem to be in great accordance with the studies of Caton [5], where the same ratio varies between 30 and $40 \%$ for an heavy duty engine: Diesel in-line 6 cylinders $(14 \mathrm{~L}, 300 \mathrm{~kW}$ at $2100 \mathrm{rpm})$. Calculations also show that the exergy recovered in the turbine is transferred to the fresh air with a 20 to $60 \%$ efficiency, for the two operating points studied here.

\subsection{Intercooler: Heat Exchanger}

Measurements of pressure and temperature upstream and downstream the intercooler are available. Equation (6) is used to take into account the impact of pressure loss on exergy variation of fresh air and becomes:

$$
\Delta E x=\Delta H-T_{0} \times \dot{m} \cdot\left(C_{p} \ln \left(\frac{T_{\text {downstream }}}{T_{\text {upstream }}}\right)-r \cdot \ln \left(\frac{P_{\text {downstream }}}{P_{\text {upstream }}}\right)\right)
$$

\subsection{Exhaust Gas}

Proceeding as described in Section 2.6 for the gasoline engine, and using Equation (6), the energy and exergy contained in the exhaust gas of the Diesel engine can be estimated and integrated to the balances shown in next paragraph.

\subsection{Energy and Exergy Balances for a Diesel Engine}

The different parts above can be summarized as follows:

Figure 7 to Figure 10 clearly show the difference between energy and exergy. For example, if we considerer the operating point $1500 \mathrm{rpm}-\mathrm{BMEP}=0.3 \mathrm{MPa}$, the energy balance shows that $57 \%$ of the energy introduced into the engine is lost in the form of heat that can be recovered. But the exergy balance shows that only $11 \%$ of the exergy introduced into the engine could be converted to useful work. In other words, only $19 \%$ of the recoverable energy could be used again to improve the engine global efficiency. This ratio is around $25 \%$ for the second operating point: $2300 \mathrm{rpm}-$ $\mathrm{BMEP}=0.8 \mathrm{MPa}$.

Considering a $25 \%$ exergy recovery efficiency (cf. Sect. 2.7), this would represent an increase of the output work of about $10 \%$.

\section{CONCLUSION}

Experimentations coupled with relatively simple calculations enable to achieve relevant energy and exergy balances for both up-to-date Diesel and gasoline engines. The difference between energy and exergy (i.e. entropy) has been taken into account. It is important to separate these two notions when heat recovery is considered in order to estimate correctly the potential increase of the engine global efficiency. Comparisons between the two engine balances are difficult because assumptions and results are quite different from one engine to the other as we can see in the item "other energies/exergies" which is larger for the gasoline engine. However, both gasoline and Diesel engine balances show that recoverable exergy seems to increase when BMEP increases, as well as the ratio recoverable exergy/recoverable energy. This means that when engine load increases, the recoverable energy contains more exergy so more potential re useable work. To sum up, recovering the energy/exergy could reasonably lead to a $15 \%$ increase of the global efficiency in the case of the gasoline engine [1], which represent a 25\% exergy recovery efficiency. And for the Diesel engine, the increase of the output work could be around $10 \%$.

One item, which has not been detailed in this paper but needs to be mentioned, is the fact that heat transfers create all the more irreversibilities, as the temperature difference of the transferring surfaces is significant. So to maximize exergy transfer during heat transfer, temperature gap needs to be low and the exchange surfaces would need to be as wide as possible but this is not realistic for vehicle, where space is limited. Thus, exergy recovery on vehicle will always implicate exergy destruction. The $15 \%$ heat recovery conversion efficiency mentioned in the work of Kensaku Yamamoto [1] illustrates this fact.

Further analysis can be made in order to decrease the weight of the category "Other energies/exergies" on the global balances. There is also a work to be done concerning the transient behavior of the engine running in a vehicle and the impact on energy recovery. 


\section{ACKNOWLEDGMENTS}

The authors acknowledge all IFP engineers who took part in this project by sharing their experiences and giving technical and technological advice.

\section{REFERENCES}

1 Kensaku Y. (2008) Advanced Hybrid Vehicle using Rankine cycle system, Honda R\&D Co., Ltd, 2008.

2 Szargut J., Styrylska T. (1964) Approximate Evaluation of the Exergy of Fuels, Brennst-Wärme-Kraft 16, 12, 589-596 [in German].
3 Flynn P.F., Hoag K.L., Kamel M.M., Primus R.J. (1984) A New Perspective on Diesel Engine Evaluation Based on Second Law Analysis, Society of Automotive Engineers, SAE paper 840032.

4 Kling R. (1980) Thermodynamique générale et applications, Édition Technip.

5 Caton J.A. (2001) A Review of Investigations Using the Second Law of Thermodynamics to Study InternalCombustion Engines, Society of Automotive Engineers, SAE paper 2001-01-1081. 